\title{
Contribuições para o design de interface de um Ambiente Virtual de Ensino Aprendizagem acessível a surdos
}

\author{
Contributions to the interface design of a Virtual \\ Learning Environment accessible to deaf people
}

\author{
Elisa Maria Pivetta, Daniela Satomi Saito, \\ Ana Margarida Pisco Almeida, Vania Ribas Ulbricht
}

ambientes virtuais de ensino aprendizagem, acessibilidade, alunos surdos virtual learning environments, accessibility, deaf students

\begin{abstract}
Este artigo apresenta os resultados de uma investigação com profissionais da educação de uma escola bilíngue para surdos em Portugal. Os entrevistados são educadores surdos e ouvintes e a pesquisa teve o propósito de recolher dados conducentes à proposta de uma estratégia de design de interface de um ambiente virtual de ensino e aprendizagem acessível a alunos surdos. Sendo ainda apresentados dados relativos às potencialidades da plataforma Moodle para a implementação desta interface. Entendendo que o desenvolvimento de ambientes acessíveis implica o conhecimento do contexto e da cultura do público-alvo, o presente artigo buscou, nas entrevistas, levantar dados que possam contribuir para as melhorias destes ambientes. A pesquisa mostra que os maiores problemas do ambiente não estão na plataforma, mas se relacionam a questões de gestão de interface e gerenciamento de conteúdo.
\end{abstract}

This paper presents the results of a research carried out with education professionals in a deaf bilingual school in Portugal. The respondents were deaf and hearing educators and the research aimed to collect data leading to the proposal of a learning management system's interface design strategy accessible to deaf students. This paper also presents data related to the potential of Moodle platform. Understanding that the development of accessible applications implies the knowledge of context and culture of the target audience, this paper aimed to collect relevant data from the interviews, for the improvement of those environments. This research demonstrates that the major problems in the environment are not concerning to the platform, but related with issues of interface and content management.

\section{Introdução}

Pessoas surdas geralmente encontram dificuldades ao interagir com interfaces digitais que foram projetados para ouvintes. As atuais propostas de ambientes virtuais, em particular as sustentadas em Learning Managment Systems (LMSs), como o Moodle, são alicerçadas 
nas lógicas da língua escrita e falada, não apresentando suporte para as línguas gestuais, e exploram de forma frágil os aspectos da visualidade, tão importante para este público.

É neste contexto que se desenha a pertinência deste estudo que, através de entrevistas e testes com o público-alvo, procurou verificar quais são as barreiras de interação e o que qualifica um ambiente adequado para pessoas surdas.

A investigação foi executada em uma escola básica e secundária de ensino bilíngue para surdos, em Portugal, tendo sido avaliados dois modelos de ambientes da plataforma Moodle. Através da pesquisa, verificou-se que os maiores problemas de acessibilidade não estão na plataforma, mas em questões de gestão de interface e gerenciamento de conteúdo.

\section{Acessibilidade digital para surdos}

A acessibilidade dos recursos web é uma premissa fundamental para a inclusão na atual sociedade. No entanto, um estudo realizado em 2012 pelo w3c.br/NIC.br indica que somente $2 \%$ das páginas web governamentais são acessíveis (W3CGT, 2012). Neste propósito, é fundamental se referir à Web Accessibility Initiative (WAI) do World Wide Web Consortium (w3c), uma iniciativa que tem como intuito apoiar o desenvolvimento de uma Web acessível, estudando e propondo diretrizes, critérios, técnicas e ferramentas auxiliares para eliminar ou minimizar as barreiras de acessibilidade nos sites. As diretrizes vigentes são as apresentadas no Web Content Accessibility Guidelines 2.0 (WCAG 2.0).

No âmbito da acessibilidade para o ensino virtual de surdos, investigadores do Institute for Language and Communication de Aachen, em conjunto com o Fraunhofer Institute for Applied Information Technology de Sankt Augustin, na Alemanha, que trabalham com Ambientes Virtuais de Ensino Aprendizagem (AVEAs), sugerem que um ambiente bilíngue torna mais fácil a comunicação e a compreensão dos conteúdos e aumenta a motivação, permitindo uma aprendizagem independente (STRAETZ, 2004).

\section{Metodologia do estudo}

1 http://www.moodle.ufsc.br 2 http://www.libras.ufsc.br

3 Modalidade escrita da língua de sinais.
Para o presente estudo foram analisados dois ambientes: o Moodle Geral $^{1}$, que segue o padrão de design da informação da plataforma Moodle, como pode ser visto na Figura 1; e o Moodle Libras ${ }^{2}$, desenvolvido para atender as necessidades do curso de graduação Letras Libras, apresentando uma proposta de design da informação que utiliza elementos representativos para a cultura surda como o sign writing $^{3}$ e conteúdos em vídeo usando a Língua de Sinais, como pode ser visto na Figura 2. 


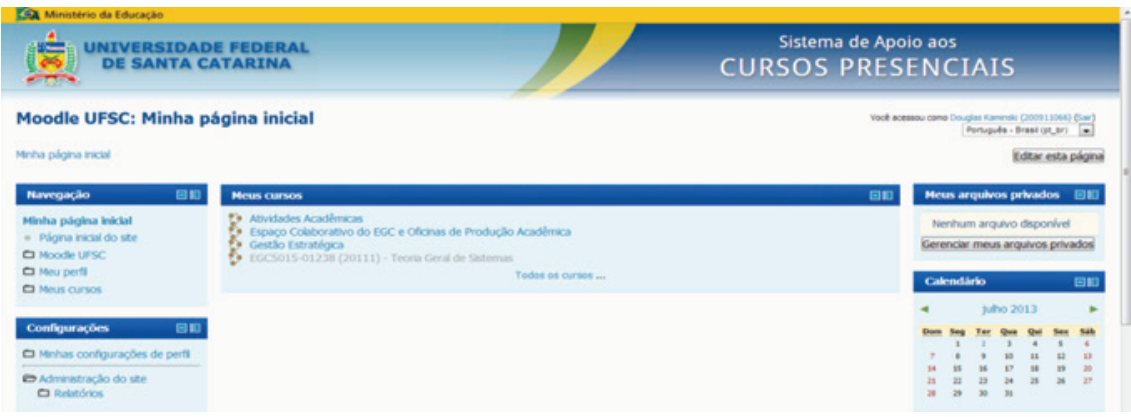

Figura 1 Design da informação do Moodle Geral (permissão de uso)

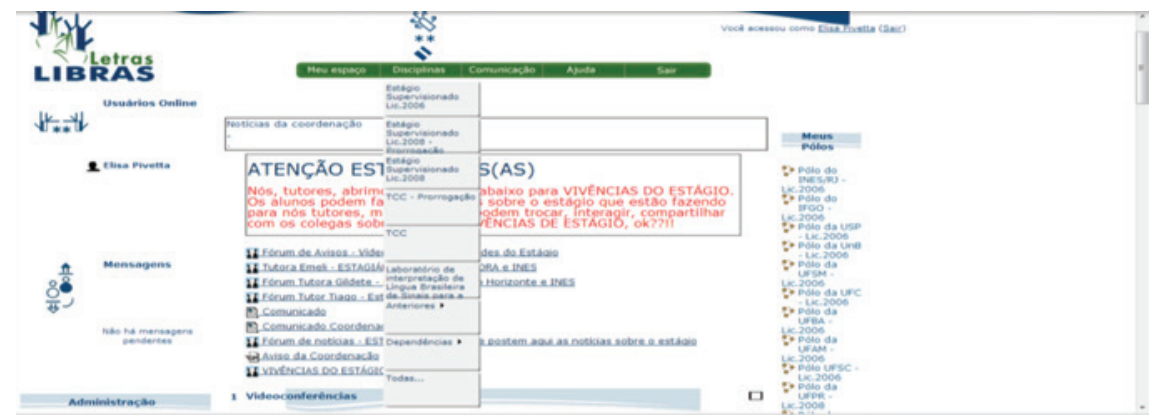

Figura 2 Design da informação do Moodle Libras (permissão de uso)

As sessões de exploração dos ambientes e as entrevistas foram realizadas na Escola Bilingue Augusto Lessa (EB1/JI), na cidade do Porto em Portugal, durante o primeiro semestre de 2013. A escola investigada faz parte do Agrupamento de Escolas Eugénio de Andrade do Porto, em Portugal. Em 2008, a escola foi instituída como referência para a educação bilíngue de alunos surdos (ALMEIDA et al., 2009). Embora a escola esteja informatizada, oferecendo acesso à internet aos seus alunos e exercitando o uso das redes sociais e software de comunicação, ela não utiliza o ambiente Moodle ou outro similar para apoio às suas práticas pedagógicas.

Após a realização de exploração dos ambientes, através de tarefas pré-determinadas, os entrevistados responderam algumas questões sobre a interação e o acesso aos ambientes. Os entrevistados foram também observados pela pesquisadora enquanto interagiam com o ambiente, e suas interações foram registradas por meio de um software de captura de tela.

As entrevistas seguiram uma abordagem metodológica de cunho qualitativo. Para as entrevistas com as professoras ouvintes, foi utilizado um protocolo de suporte a entrevistas semi-estruturadas, partindo do princípio de Quivy e Campenhoudt (2005), que visa explorar de forma aberta e flexível um campo onde não há conhecimento prévio. Nas entrevistas com os formadores surdos foi empregado como instrumento, um questionário semi-estruturado, que Lakatos e Marconi (2011) chamam de assistemático, onde o 
entrevistador possui a liberdade de explorar e se aprofundar nas questões que julgar relevantes.

A opção por entrevistados que atuam na educação bilíngue para surdos em Portugal ocorreu em virtude da atuação direta na área de interesse da pesquisa, bem como pela tradição da instituição. Outro fator de escolha, é que a escola não utiliza o ambiente Moodle em suas práticas de aula. Nielsen (1993) sugere que o software deve ser intuitivo e pessoas sem prática ou conhecimento prévio devem interagir livremente. Assim, entende-se que o perfil dos usuários tem impacto no desempenho do método e pode-se obter um resultado mais significativo quando os usuários não adquiriram habilidades, rotinas e vícios de interação.

Dos cinco formadores surdos, da referida escola, foram entrevistados quatro, todos Licenciados em LGP e mais dois professores ouvintes, pessoas diretamente envolvidas com a educação de surdos. O Quadro 1 ilustra o perfil destes entrevistados. A Entrevistada E1, também atuou como intérprete nas entrevistas com os formadores surdos. A entrevistada E2 é também terapeuta da fala.

Quadro 1 Perfil dos entrevistados (elaborado pelos autores)

\begin{tabular}{lllllll}
\hline Entrevistados & (E1) & (E2) & (E3) & (E4) & (E5) & (E6) \\
\hline Função & Professora & Professora & Formadora & Formadora & Formadora & Formadora \\
Formação & Doutoranda & Doutoranda & Lic. LGP & Lic. LGP & Lic. LGP & Lic. LGP \\
LGP & Domina & Domina & Domina & Domina & Domina & Domina \\
Surdez & Não & Não & Profunda & Profunda & Profunda & Profunda \\
\hline
\end{tabular}

\section{Resultados}

Após as sessões de exploração dos ambientes e entrevistas, os dados coletados foram tabulados e as entrevistas transcritas. Como resultado, são apresentadas informações acerca da realidade escolar e as avaliações sobre os dois ambientes selecionados para a pesquisa.

\subsection{Realidade escolar}

De acordo com as entrevistadas E1 e E2, as turmas bilíngues da EB1/ J1, são formadas apenas por alunos surdos que utilizam a LGP, isto é, alunos que não conseguem integrar-se em outras turmas com alunos ouvintes. Nas turmas bilíngues a LGP é a primeira língua e a LP a segunda, seja ela em sua modalidade oral ou escrita. As turmas bilíngues caracterizam-se por possuir em sala de aula um formador surdo e um professor especializado. Segundo as entrevistadas, a 
modalidade escrita da LGP, o sign writing, não é ensinada nos agrupamentos, pelo fato de ser uma modalidade de escrita recente e que ainda não está bem delineada.

Segundo relatos, mesmo com os esforços realizados, a interação de alunos surdos e ouvintes em sala de aula ainda é limitada. Verificou-se uma tendência de aumento das dificuldades de integração à medida que a idade dos alunos avança e aumenta o uso da comunicação em LS pelos surdos. Segundo as entrevistadas E1 e E2, mesmo que o aluno ouvinte tenha aulas de língua gestual, ele não consegue atingir um nível satisfatório de domínio que lhe permita ter conversas com seus pares.

No âmbito do ensino-aprendizagem, os processos de avaliação dos alunos surdos têm se modificado ao longo dos anos. Atualmente, os alunos que estão integrados fazem a mesma prova dos ouvintes: os alunos bilíngues podem responder às provas de avaliação tanto em LGP como em LP, no entanto, se a finalidade é avaliar a LGP, a avaliação ocorre em LGP, sendo que a mesma lógica se aplica à LP. Ainda é possível recorrer à LGP em avaliações de diferentes domínios. No segundo semestre de 2012, as turmas do quinto ao nono ano realizaram o exame de História em LGP. Para tanto, o intérprete realizava as perguntas em LGP e os alunos davam as respostas em LGP, sendo as mesmas filmadas. Dada a complexidade da tarefa, foi adotado um tempo maior para que os alunos fizessem as provas.

Sobre tecnologias digitais, elas são mais utilizadas em atividades de lazer, do que com atividades formais de ensino-aprendizagem. Redes sociais, vídeos, imagens e aplicações de videoconferência são bastante utilizados, visto que o vídeo agrega a possibilidade dos alunos se comunicarem uns com os outros. Em relação ao uso das redes sociais, a entrevistada E2 destaca: “(...) no Facebook eles não se inibem; nós notamos que os surdos têm aquela resistência à escrita e no Facebook eles comentam, escrevem, não se inibem. Eles gostam muito, eles são fãs”.

Ao longo dos cinco anos de existência do ensino bilíngue em Portugal, muitas mudanças foram observadas. No entanto, sob a ótica das entrevistadas, a atual lei ainda não está implementada em sua plenitude e outras mudanças precisam ser realizadas. No modelo atual, por exemplo, poucos professores são contratados como efetivos, sendo os demais contratados por tempo determinado de quatro anos. Esta periodicidade de mudanças dificulta a estabilização das equipes de ensino, além de dificultar a formação de profissionais com proficiência linguística. No caso particular dos formadores e dos terapeutas da fala, a validade da "colocação" é de apenas um ano, agravando mais ainda a situação relatada. 


\subsection{Os formadores surdos}

4 http://pt.surveymonkey. com/mp/likert-scale/
As entrevistas com os formadores surdos foram realizadas em LGP com o auxílio da entrevistada E1 que, nesta ocasião, atuou como intérprete. As entrevistas foram filmadas e gravadas em áudio, para capturar a fala da intérprete, tendo durado de 70 a 90 minutos. As quatro entrevistadas não conheciam o Moodle, apenas ouviram falar da plataforma. Em geral, observou-se, através das respostas das entrevistas, que o ambiente Moodle Libras é mais "amigável" do que o Moodle Geral. No entanto, em ambos os ambientes os usuários apresentaram dificuldades de interação, tal como apresentamos detalhadamente decorrer destas seções do presente artigo.

O questionário aplicado possuía quatro perguntas englobando ações de acessibilidade envolvendo a navegação pelas páginas, rótulos, menus, imagens, gráficos, vídeos e a realização das tarefas. As respostas das perguntas pré-definidas foram avaliadas com base na escala de Likert ${ }^{4}$, variando de: discordo totalmente, com nota 1, a concordo totalmente, com nota 5. As respostas podem ser visualizadas no Quadro 2. A sigla "nc" significa que o entrevistado não conseguiu encontrar conteúdo em forma de vídeo.

Quadro 2 Avaliação do ambiente Moodle (elaborado pelos autores)

\begin{tabular}{|c|c|c|c|c|c|c|c|c|}
\hline Acessibilidade em: & E3 & E4 & E5 & E6 & E3 & E4 & E5 & E6 \\
\hline Navegação e interação & 2 & 3 & 3 & 3 & 4 & 2 & 3 & 3 \\
\hline Rótulos, menus, títulos & 2 & 3 & 4 & 3 & 5 & 3 & 5 & 4 \\
\hline
\end{tabular}

Durante a realização das atividades, vários comentários foram colocados a respeito da acessibilidade de ambos os ambientes. Estes comentários estão descritos na próxima seção. Também ocorreram situações em que, mesmo não conseguindo realizar a tarefa, as entrevistadas avaliaram positivamente os ambientes por não gostar de dar avaliações negativas. Neste caso, foi necessário realizar uma intervenção para não prejudicar os resultados.

\subsubsection{Acessibilidade na navegação e interação com ambiente}

Em relação à acessibilidade de navegação no Moodle Geral (Figura 1), uma das barreiras identificadas foi em relação às cores. Cores de textos e links bem definidas e contrastantes em relação ao fundo de página são primordiais para usuários visuais como os surdos. Três 
das quatro entrevistadas demoraram a encontrar uma disciplina que fazia parte de uma tarefa. Passaram várias vezes pelo link e não o visualizaram, mesmo com o link em questão localizado na região de maior visibilidade dentro dos padrões da cultura ocidental. A forma de leitura é confirmada pela entrevistada E3, que diz: "visualizamos de cima para baixo".

No mesmo ambiente, a dificuldade de interação com os links se deu em virtude das relações entre as cores utilizadas. A entrevistada $\mathbf{E} 4$ relata: "ando pelas páginas, é sempre a mesma cor e não percebo qual a lógica, porque mudou a cor para uma disciplina”. Ela ainda corre o olhar pelo site e diz novamente: "a primeira não é, a segunda não é, me perdi na outra cor, pois é diferente”. A entrevistada custou a perceber o link para a disciplina devido à cor cinza em relação às demais que eram azuis. Por fim, ao avaliar os dois ambientes, sugere que ambos deveriam "melhorar sem dúvida na cor".

Os entrevistados foram unânimes ao afirmar que ambos os sites estavam com muitas informações, apesar de considerarem o Moodle Libras um pouco melhor. Citaram a importância de categorizar os itens e subitens e imbricá-los sempre que possível para não "poluir" muito o ambiente. A entrevistada E3 sugere que é importante categorizar os links e coloca-los mais no início da página, isto é, na parte superior, não os misturando com o conteúdo do site.

No Moodle Geral, a entrevistada E6, ao ter dificuldades na realização das tarefas faz um comentário:

"A informação não está bem clara, tem muita coisa, tem muita coisa pequeninha, na minha opinião, teria que ter só a informação principal e clicava e ia aparecendo, encontrando atrás mais informações. Tem muita informação ao mesmo tempo, fica melhor uma dentro da outra. É mais rápido, perde menos tempo. Se não tem que ler tudo, ler tudo, é difícil." (E6, tradução de entrevista realizada em Língua de Sinais na EB1/J1)

A entrevistada E3 ficou com dúvidas ao clicar em um link que aparentemente não abriu. Da mesma forma, a entrevistada E6, ao encontrar um link de uma tarefa, clica com o mouse e fica indecisa, pois não vê acontecer nada e pergunta: “Tem que clicar duas vezes?”. O clique sobre o link abria a opção de download do arquivo, que depois de ser descarregado, permanecia na barra de tarefas sem que as entrevistadas o percebessem. Este tipo de problema poderia ser resolvido nas configurações de sistema, na própria máquina. Colocar uma explicação sobre o tipo de arquivo que será aberto ao lado dos links de download seria uma medida significativa. 


\subsubsection{Acessibilidade nos rótulos, menus e títulos}

A entrevistada $\mathrm{E} 4$ comenta que o menu das disciplinas do Moodle Libras é melhor de visualizar do que o Moodle Geral. Ela diz: "percebo melhor a divisão", apontando para o menu pop-up. "Está mais separado, se for tudo seguido, não percebo bem. Fica melhor, mais esquemático. A luz, ao clicar com o mouse no menu, deixa a informação mais visível", se referindo ao comportamento do menu, que evidencia o link, quando passa com o mouse sobre as opções.

Enquanto tenta resolver uma atividade solicitada no Moodle Geral, a entrevistada E3 diz: "As palavras estão muito pequenas e a cor muito clara, deviam estar mais escuras, com letras maiores, fico muito cansada, muito texto, texto, texto". Sobre as cores dos rótulos, a entrevistada E4 diz "Melhor usar uma cor que salienta o fundo, para salientar a informação que preciso. Cores batidas não", se referindo ao azul de texto com o azul mais claro de fundo.

A intérprete, percebendo novamente a dificuldade da cor, discorre:

“(...) tem que ser apelativo visualmente, normalmente os surdos vão pelo que chama mais atenção. Se uma imagem é muito complexa eles não abstraem como nós. Em uma investigação com surdos e ouvintes a estar a fazer um desenho onde as informações iam sendo descritas. No fim, ao comparar os desenhos, saíram completamente diferentes. O surdo fez o desenho tal e qual como as descrições, por exemplo, havia flores na camisa do tipo cone, com bico, em forma de caracol ...não sei o que, não sei o que... no fim os ouvintes fizeram umas flores quaisquer, enquanto o desenho dos surdos ficou muito realista... os surdos são muito visuais, são capazes de descrever ou desenhar... os caracois descem na testa, 1/4 da testa mais a direita etc... E o contrário é mesma coisa, quando eles veem uma imagem muito complexa eles extraem os pormenores e perdem o sentido global, pegam o que chama mais atenção". (E1, comentários realizados ao longo de entrevista na $E B 1 / J 1)$

No Moodle Libras, a entrevistada E5 encontrou maior facilidade em resolver a tarefa na estrutura de links do menu da segunda atividade do que na primeira. Na segunda atividade o nome da disciplina era apresentado como TCC, uma abreviação de Trabalho de Conclusão de Curso, enquanto na primeira atividade, o nome da disciplina era apresentado por extenso. As professoras E1 e E2, explicaram a maior facilidade de identificação dizendo que os surdos gravam mais facilmente as siglas. Todavia, a WCAG 2.0 (2013) indica que é necessário dispor de um mecanismo para identificar definições específicas de palavras ou expressões utilizadas de forma restrita no uso de siglas e jargões. Outro fato a ter cuidado é o emprego de palavras não muito usuais. A palavra "laudas", do português do Brasil, provocou o questionamento de uma entrevistada, pois ela não sabia 
o que significava e a interprete também não. Muitas das palavras do dicionário português não possuem uma representação em LGP ou são inteligíveis para o surdo.

Ainda no Moodle Geral, não conseguindo realizar as tarefas, a entrevistada E6 encontrou uma opção de pesquisa no site (busca), localizada na parte inferior do site à esquerda e que tratava de: "Pesquisa nos Fóruns". Como era uma opção para pesquisar somente dentro dos fóruns, e esta não era a proposta da atividade ela não encontrou uma resposta válida. Assim, a entrevistada disse: "O melhor seria procurar por palavras-chave", fazendo um sinal de que uma informação deveria estar imbricada dentro da outra. Como sugestão, a opção de pesquisar, quando se refere apenas a um determinado assunto dentro do site, deveria estar junto a esta opção e não na página geral, como na proposta avaliada.

A entrevistada $\mathrm{E} 6$, na tentativa de realizar a primeira tarefa, diz: "Não tenho paciência, falta a informação clara". Já a entrevistada E3 diz: "Tópicos muito confusos, deveriam estar mais padronizados, ao olhar na tela deveria ver facilmente que não é esta, não é esta, não é esta. Assim obriga ler tudo, tudo, a procura do que eu quero. Perco muito tempo".

Questionando-se à entrevistada E4 qual foi a sua dificuldade, ela responde: "Letras pequenas, nomes confusos, em formatos e cores diferentes". A entrevistada sugere também que os assuntos deveriam estar melhor identificados e categorizados, para poder encontrar mais facilmente o que está dentro dos arquivos, pois considera complexo ler textos longos.

Sobre a presença do sign writing no Moodle Libras, as entrevistadas comentaram que sabiam da sua existência. As entrevistadas E2 e E3 tiveram contato com a modalidade na universidade, mas afirmaram saber pouco, praticamente nada. A Entrevistada E5, diz: "É importante, mas para as pessoas perceber é difícil”.

\subsubsection{Acessibilidade em imagens, gráficos e ícones}

Em relação à acessibilidade das imagens, a entrevistada E3, ao interagir com o Moodle Libras, encontrou algumas fotografias e comenta: "não consigo encontrar as tarefas e vejo uma imagem que não consigo relacionar", se referindo a uma fotografia de uns óculos. E continua: "é a introdução de uma tarefa, mas tem a fotografia de um óculos. O problema é perceber o que isto é, se é um dicionário, se é para procurar. Vejo uma imagem que não consigo relacionar, na ideia geral não percebo a lógica da imagem”. Faz uma crítica em relação ao contexto em relação às fotografias. E continua a se expressar:

“... gosto de desenhos, é mais engraçado, é mais visual, capta mais atenção, a fotografia é mais suave, eu prefiro o desenho é mais forte. A fotografia causa mais dúvida, causa mais distração. As 
fotografias têm muitos elementos distratores, que distraem, não sei explicar melhor, mas tá confuso. Se o objetivo era mostrar a interprete tinha que mostrar só a interprete. Poderia ter a fotografia com a intérprete e o texto. Estou a pensar porque tem isto. A cadeira, por exemplo, não é importante aqui. Se o objetivo era a intérprete, deveria ter só a fotografia dela, fica confuso, deveriam ser mais objetivas". (E3, tradução de entrevista realizada em Língua de Sinais na EB1/J1)

A entrevistada $\mathrm{E} 4$ diz: "não vi grande imagens, para um surdo é importante ter mais imagens ou ter palavras mais claras, ou então se os conceitos são mais difíceis seria bom inserir imagens associadas". Para a entrevistada E5 uma maneira de melhorar os ambientes é "colocar uma imagem significativa e ligar com uma explicação em vídeo na linguagem gestual, senão tem que chamar sempre alguém para ajudar. Deveria ter várias imagens e vídeos que pudesse ver, escolher e clicar ou imagens que abrissem janelas com intérpretes".

Sobre a importância das imagens a E6 discorre: "Se existe língua gestual a imagem não precisa, mas depende, se for uma imagem para informar é importante. Se tem imagem, tradução em língua gestual e texto, tem que abstrair. Um surdo olha para um lado, olha para outro e não sabe para onde olhar. Depende, para estes assuntos as imagens não resolvem, é complexo". Se referindo ao que trata a página no momento da pergunta que são conceitos sobre as palavras sistema e paradigma.

\subsubsection{Acessibilidade em vídeos}

É unânime a importância dos vídeos para pessoas com surdez e, em especial, dos vídeos com língua de sinais. Os vídeos que não estão em língua de sinais devem conter legenda e dar a possibilidade de controle ao usuário para que ele possa parar, retroceder, ver o vídeo em câmera lenta e cancelar a reprodução, conforme a sua necessidade.

Nas entrevistas, a E4, estando no Moodle Libras, por duas vezes clicou no link onde tinha a palavra "vídeo" e não encontrando tal vídeo, disse: "me senti enganada". A entrevistada E5 também clicou na mesma opção. Na verdade, o link selecionado pelas entrevistadas não era um link para vídeo e sim, um título que continha um link para um fórum, que dizia: "Fórum de Avisos - Vídeos sobre as atividades do Estágio”. Como os surdos possuem estratégias de leitura diferentes, buscando por palavras-chave, clicaram sobre o link e se sentiram frustrados.

A Entrevistada E5 diz: "Falta imagens, não há vídeos, pra mim é importante. Mesmo que eu consiga ler, não é só a palavra, tem que perceber a ideia, e o vídeo ajuda a perceber a lógica e a ideia. $O$ vídeo pode ser complementar com o escrito; vídeo e escrito. Eu leio as palavras, mas depende, se for uma frase muito complexa, às vezes 
perde a lógica e qual é a ideia que querem. Então, se tiver o vídeo já percebi qual é a ideia de que estão a dizer".

\section{Considerações finais}

No final das sessões de exploração dos dois ambientes Moodle estudados verificou-se que as entrevistadas tiveram algumas dificuldades na realização das atividades, sendo que somente uma conseguiu realizar todas as tarefas propostas. Não foi pré-definido um tempo para a realização das tarefas, pelo que, no caso das entrevistadas que não conseguiram realizar todas as tarefas previstas, o tempo se esgotou naturalmente e resolveram parar.

As principais barreiras encontradas, de modo geral, foram de interface mal projetada e design de informação pouco estruturado e organizado. Muitas destas não são limitadoras da interação apenas para os surdos, sendo igualmente barreiras para os usuários em geral como é o caso da funcionalidade de download de um arquivo do site, ficando o arquivo na parte inferior na barra de tarefas, o que muitas vezes não é observado. Problemas quanto ao tamanho dos objetos também atingem usuários ouvintes, assim como problemas no acesso e localização de informação; a este propósito, veja-se o caso da falta de um recurso de busca que dificulta a localização de conteúdos. Com efeito, o recurso de busca, de acordo com Nielsen (1993), é um importante elemento de interface em um website de grande porte.

A premissa de usar cores que contrastam, já faz parte das normas de acessibilidade da w3c. O problema com as cores relatado nesta investigação, também pode afetar pessoas que possuem dificuldade de visão ou até mesmo as que não possuem problemas sensoriais. No entanto, o problema maior fica para as pessoas que possuem perturbação em algum dos sentidos, que é o caso dos surdos, que são extremamente visuais.

A imagem é uma componente fundamental do processo de educação bilíngue para alunos surdos, sendo um recurso fundamental para a aprendizagem. No caso dos surdos, a imagem não é apenas ilustrativa ou decorativa; é uma linguagem alternativa, devendo, e tal como sugere Almeida et al. (2009), ser aplicada de forma diferente por comparação com o caso dos alunos ouvintes. Ora, neste estudo observou-se que, em algumas situações, o uso da imagem prejudicou a acessibilidade. A imagem deve ser perceptível, limpa, clara, para que o surdo consiga abstrair a ideia. Em casos onde o conteúdo é complexo, para informar claramente com imagem, é importante utilizar formas alternativas como vídeo em língua de sinais, palavras-chave ou até mesmo desenhos gestuais, para não prejudicar o entendimento da informação.

Quanto ao emprego de imagens do tipo fotografia, observa-se o cuidado deste meio de expressão. Em condições de refletir a realidade é um meio riquíssimo; porém, se mal empregada pode causar 
confusão, visto que os surdos abstraem deste universo as evidências e procuram trazer para a realidade o que nela contem, buscando nos pormenores entender o que a imagem esta transmitindo.

No caso de imagens dinâmicas, a possibilidade de ter no ambiente digital uma ferramenta de vídeo-conferência, que permita a comunicação visual, agrega a possibilidade de alunos surdos comunicarem não apenas entre eles, mas também com os alunos ouvintes e vice-versa. Outra questão importante é em relação ao uso de legendas em vídeo. Não há como negar a importância deste recurso, observando a diversidade de perfis de surdos. Porém, nem sempre elas são efetivas em seu objetivo; por exemplo, uma legenda pode conter palavras que não constam do dicionário da língua de sinais, ou também ser muito rápido, visto que os surdos possuem dificuldade de ler em português. Sugere-se que todo o vídeo tenha funcionalidades de parar, avançar, retroceder e, se possível, visualização em "câmara lenta".

Com relação à escrita, especificamente no que respeita à modalidade de sign writing, verificou-se, neste estudo, que esta é uma modalidade ainda "difusa" pelos entrevistados surdos.

Quanto ao desenvolvimento de AVEAs acessíveis e especificamente ajustados às particularidades das comunidades e culturas dos alunos surdos, este estudo permitiu compreender a importância de recorrer às modalidades "visuais" de informação. Segundo Almeida et al. (2009, p. 45) "a resposta pedagógica para um aluno surdo deve ser pensada para quem vê e não ouve, para quem olha, para quem observa, para quem todos os processos cognitivos dependem do olhar". Convém, portanto, que estes ambientes sejam desenvolvidos de forma a valorizar esta componente visual de forma a não comprometer os processos de interação, motivação, concentração e memorização destes alunos. Neste sentido, os maiores problemas do ambiente não são da plataforma, estando diretamente ligados a questões de gerenciamento de interface e de conteúdo. Todavia, é importante salientar que é possível adicionar melhorias, como novas ferramentas ao ambiente.

Em síntese, o estudo aqui apresentado permitiu sistematizar um conjunto de preocupações consideradas fundamentais no desenvolvimento de ambientes acessíveis a surdos, nomeadamente no que respeita ao design da informação visual e estruturação das interfaces. Recomenda-se, para valorizar o componente visual: evitar textos longos; evitar sistemas de navegação exclusivamente baseados em texto; cuidados com o uso de cores, implementar mecanismos de controle de velocidade das legendas; estudar formas de realizar ajustes específicos de acessibilidade com vista a uma conformidade plena com a WCAG 2.0; estudar formas de integrar ferramentas das redes sociais nestes ambientes; sensibilizar, apoiar e qualificar as equipas de apoio e desenvolvimentos dos AVEAs para a realidade da surdez; propor estratégias de colaboração entre os diferentes intervenientes (developers, designers, técnicos, professores e alunos). 


\section{Agradecimentos}

À CAPES, pela concessão de bolsa - processo n. 18444-12-1. A todos os entrevistados e à Escola Bilingue Augusto Lessa, pela disponibilidade e colaboração.

\section{Referências}

ALMEIDA, D. et al. (2009). Educação bilíngue de alunos surdos: Manual de apoio à prática, Ministério da Educação. Lisboa: Cercica.

LAKatos, E. M.; Marconi, M. A. (2011) Metodologia Científica. 5ª ed., São

Paulo: Atlas.

NIELSEN, J. (1993). Usability Engineering. Ed. Elsevier.

QUIVY, R., CAMPENHOUdT, L. V. (2005). Manual de Investigação em Ciências Sociais.

Ed. Gradiva, 4. ed.

straetz, K. et al. (2004). An e-Learning Environment for Deaf Adults. In: 8th ERCIM Workshop. User Interfaces for All 2004. Proceedings... Viena, Austria, 2004.

WCAG 2.o. (2012). Web Content Accessibility Guidelines 2.o. W3C Accessibility Initiative. Disponível em: <http://www.w3.org/TR/WCAG20/>. Acesso em out. 2012.

w3CGT. (2012). Acessibilidade. Disponível em: <http://www.w3c.br/GT/Grupo Acessibilidade\#w3c_inicio_conteudo>. Acesso, em dez 2012.

\section{Sobre as autoras}

\section{Elisa Maria Pivetta}

<elisa@cafw.ufsm.br>

Mestrado em Ciências da Computação pela UFSC, doutoranda do EGC/UFSC em estágio doutoral na Universidade de Aveiro Porugal. Professora da UFSM (Universidade Federal de Santa Maria) Experiência na área de Ciência da Computação, com ênfase em Sistemas de Informação, atuando principalmente nos seguintes temas: Multimídia, Informática na Educação, Interação Humano-Computador e Acessibilidade na Web.

\section{Ana Margarida Pisco Almeida \\ $<$ marga@ua.pt $>$}

Mestrado em Comunicação Multimédia e programas doutorais em Multimédia em Educação e Informação e Comunicação em Plataformas Digitais. Os seus interesses de investigação estão relacionados com as áreas da inclusão digital e $e$-health, tendo desenvolvido trabalhos maioritariamente relacionados com os públicos específicos, sobretudo com cidadãos com necessidades especiais e ainda relacionados com as dinâmicas de comunicação em saúde. 


\section{Daniela Satomi Saito}

$<$ daniela.saito@gmail.com>

Mestrado em Ciências da Computação pela UFRGS, MBA em Gestão de Pequenas Empresas de Base Tecnológica pela UEL e doutoranda do PPG em Engenharia e Gestão do Conhecimento da UFSC. Professora do Instituto Federal de Educação, Ciência e Tecnologia de Santa Catarina (IFSC), campus Palhoça Bilíngue (Libras/Português). Atua principalmente nas áreas: Multimídia, Informática na Educação, Interação Humano-Computador e Acessibilidade Web.

\section{Vania Ribas Ulbricht}

< vulbricht@gmail.com>

Doutorado em Engenharia de Produção pela Universidade Federal de Santa Catarina (1997). Atualmente é professora visitante do PPGDesign-UFPR é pesquisadora da Université Paris 1 (PanthéonSorbonne) e docente voluntária na UFSC no Programa de PósGraduação em Engenharia e Gestão do Conhecimento. Pesquisa e publica em Educação com ênfase em Tecnologia Educacional, e Acessibilidade e Geometria Descritiva.

Artigo recebido em 8 out. 2013, aprovado em 12 dez. 2013. 